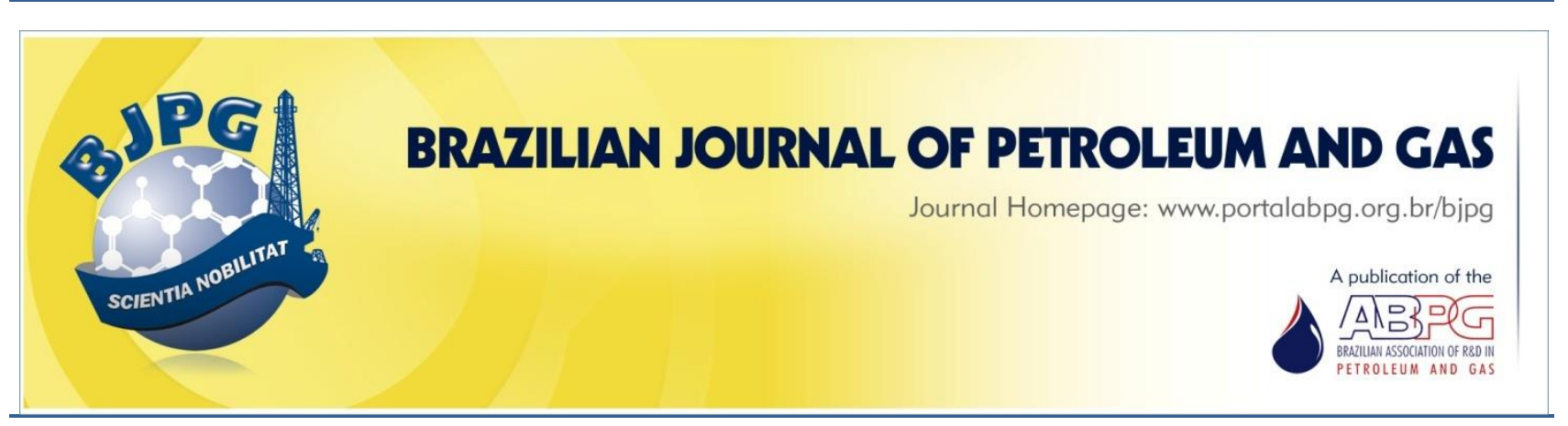

\title{
EVALUATION OF CAPILLARY END EFFECT IN WATER-OIL PERMEABILITY TESTS USING MULTIPLE FLOW RATES TECHNIQUE
}

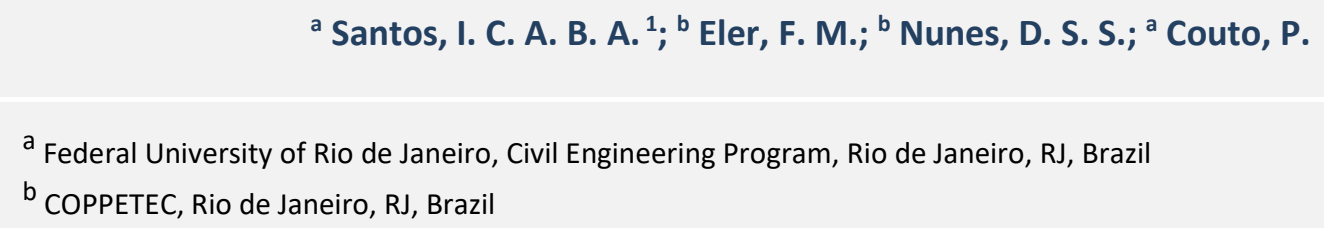

Received: 22.11.2020 / Revised: 14.12.2020 / Accepted: 14.12.2020 / Published on-line: 07.01.2021

\begin{abstract}
Relative permeability curves obtained in laboratory are used in reservoir simulators to predict production and establish the best strategies for an oil field. Therefore, researchers study several procedures to obtain relative permeability curves. Among these procedures are the multiple flow rates injection methods. Thus, this work proposes to develop an experimental procedure with multiple increasing flows. To make this feasible, simulations were initially carried out at CYDAR, aiming to establish flow rates and time necessary to achieve system stabilization, within the limits of the equipment. After that, tests were carried out establishing the minimum time of 5 hours to stabilize the oil production, and the differential pressure at each flow rate. The accounting and minimization of the capillary end effect in these tests were also evaluated. Capillary pressure constraints contributed to minimize the number of possible solutions to the optimization problem improving the fit of solutions for a specific case.
\end{abstract}

\section{KEYWORDS}

relative permeability; multiple flows rates; CYDAR; capillary end effect

\footnotetext{
${ }^{1}$ To whom all correspondence should be addressed.

Address: Federal University of Rio de Janeiro, Civil Engineering Program, Av. Athos da Silveira Ramos, 149, Technology Center Bloco B, sala 101 - Ilha do Fundão, Rio de Janeiro, RJ, Brazil.

Phone number: +55 (88) 98883-6855 | e-mail: isabelly.santos@coc.ufrj.br doi:10.5419/bjpg2020-0019
} 


\section{INTRODUCTION}

Relative permeability is one of the most important data for reservoir engineering. Relative permeability curves obtained in the laboratory are used in reservoir simulators to predict oil production and decide the best strategies when exploring an oil field (Cruz, 2015).

The tests to obtain these curves, in a water-oil system, are performed on rock samples from the reservoir or on representative outcrops. These are often subjected to displacement tests in an unsteady-state regime, in which an attempt is made to repeat fluid displacement processes that take place in the oil reservoirs during secondary recovery activities. In the test, capillary and viscous forces act in rock sample, as well as in petroleum reservoirs (Al-Mjeni et al., 2011; Cruz, 2015).

Usually, this experiment is conducted by injecting water at a single constant flow rate. The experimental data obtained (differential pressure and produced volume of oil) is treated using analytical techniques, such as that of JBN (Johnson et al., 1959), or through history matching, to obtain parameterized relative permeability curves $\left(K_{r}\right)$.

However, these tests have limitations since conditions that are intrinsic to the laboratory. Real reservoir flows present different characteristics, such as the presence of capillary end effect. This happens due to a discontinuity in capillary pressure at the end sample outlet, causing an erroneous residual oil saturation (Gupta \& Maloney, 2016; Hadley \& Handy, 1956).

Besides, many mathematical methods used to infer $K_{r}$, such as the JBN, do not consider the capillary forces. Also, the history matching method can be limited since it does not guarantee the uniqueness of solution if used in experiments with only one injection flow rate. This can generate bias in the relative permeability obtained in the laboratory (Ucan et al., 1997).

In the context described, the present work proposes to develop an experimental procedure of multiple flow rates to obtain the relative permeability curves, based on the theoretical methodology proposed by Lenormand and Lenormand (2016).

The greatest advantage of this method is the accounting of the oil that was retained in the sample due to the capillary end effect.
Furthermore, this method makes it possible to determine both capillary pressure $\left(P_{c}\right)$ and relative permeability $\left(K_{r}\right)$ in a single experiment while adding a capillary pressure constraint to improve the uniqueness of the history matching process.

\section{RELATIVE PERMEABILITY EXPERIMENTS}

During the reservoir drilling process, rock cores are extracted, undergoing several laboratory tests to determine properties of relevance for oil extraction, such as porosity, permeability, and capillary pressure. Laboratory experiments must be carried out at reservoir conditions so that the results obtained are representative of the field.

In Figure 1, one of the most used core flooding experiments to determine $K_{r}$ - the unsteady state relative permeability- is presented. The UnsteadyState (USS) method consists of displacing the fluid that saturates the porous medium by injecting another fluid at constant flow or constant pressure (Rios et al., 2012).

For a water-oil system, an oil-saturated core with immobile water $\left(S_{w i}\right)$ is first accommodated in the holder. This condition is representative of the initial state of the reservoir before the injection of fluids for its exploitation. Then, it is performed a water injection in the inlet face, while oil is produced at the outlet face. During the test, the produced oil volume and the differential pressure across the core are recorded.

The most used laboratory procedures in the water-oil relative permeability tests consist of the injection of water at a single flow rate, obtaining the residual oil saturation (Sor). The $S_{\text {or }}$ can be affected greatly by the capillary end effect (Bauget et al., 2012). Thus, to minimize laboratory artifacts, a sudden increase in flow rate (bump flow) is performed at the end of the test. There is often an additional production of oil-related to the increase in differential pressure caused by the bump flow (Cruz, 2015).

For identification purposes, the residual oil saturation $\left(S_{o r}\right)$ will be called remnant $S_{\text {or }}\left(S_{o r}^{r e m}\right)$ when it is obtained in a test with only one injection rate, and bump $S_{\text {or }}\left(S_{\text {or }}^{\text {bump }}\right.$ ) when there is an increase in flow rate (bump flow). 


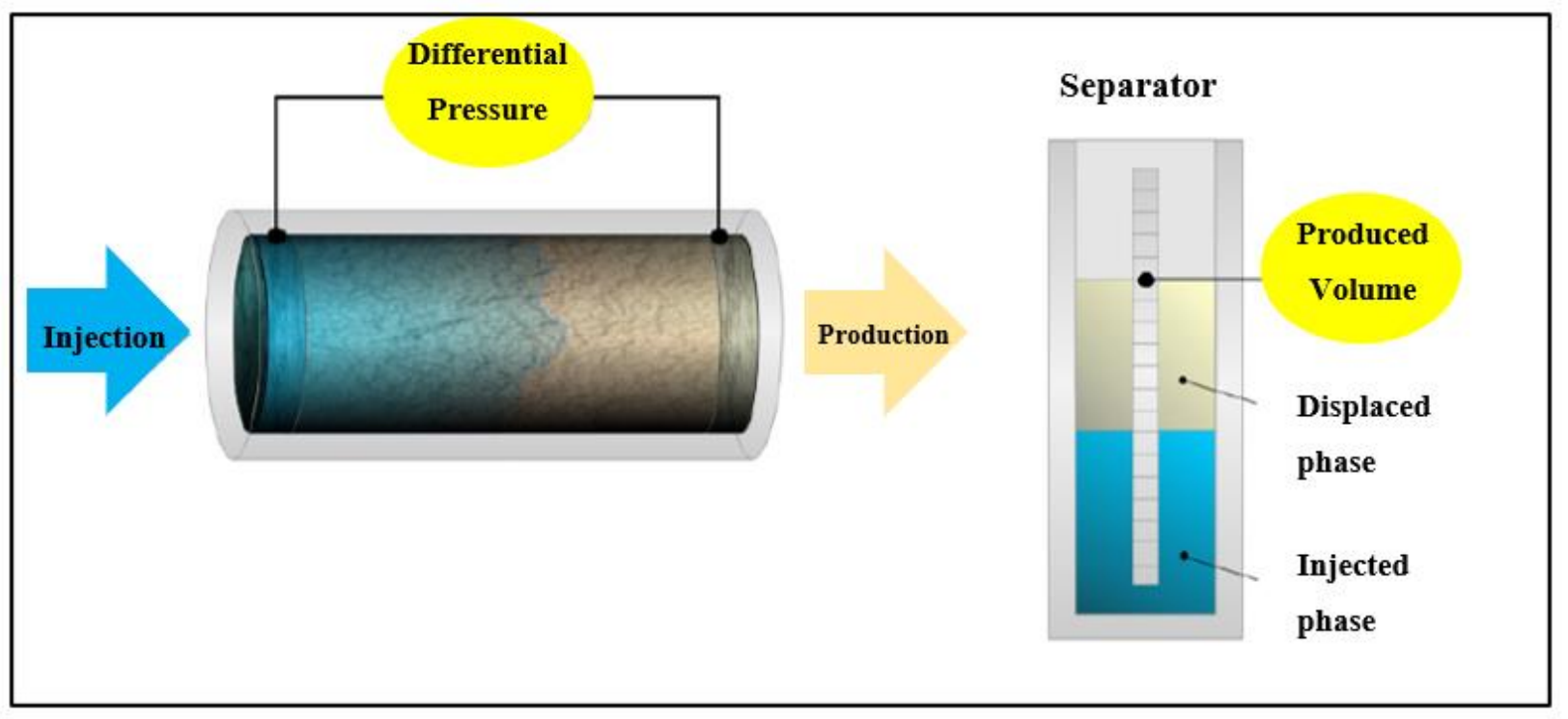

Figure 1. Scheme of the relative permeability test in transient regime (adapted from Ambrus et al., 2004).

\section{CONVERTING LABORATORY DATA TO RELATIVE PERMEABILITY}

Relative permeability curves are inferred from differential pressure and oil production data collected in these tests. The solution techniques normally applied are analytical solutions, such as JBN (Johnson et al., 1959) and Jones and Roszelle (1978), based on the Buckley-Leverett model for the displacement of immiscible fluids.

This method assumes simplifications such as one-dimensional flow, negligible capillary pressure, and homogeneous porous medium. These simplifications hardly represent the reality of the displacement tests performed in the laboratory (Ambrus et al., 2004; Viegas, 2017).

Another technique very used is the history matching (Rosa et al., 2006), which is a non-linear regression problem. The procedures of this nature use parameterized $K_{r}$ curves in a numerical flow simulator and an optimization process finds the parameters that best represent the experimental data. In this type of technique, the flow model can be simplified or not.

The advantage of this method is the possibility of including all effects that may be relevant in the actual displacement process, such as capillary pressure, medium heterogeneity, fluid compressibility, or gravity (Ambrus et al., 2004;
Wang, 2014). However, many software that use the non-linear regression method do not include these effects in the theoretical model, analyzing the data up to $S_{o r}^{r e m}$, as in JBN $($ Cruz, 2015).

\section{MULTI-STEP PROCEDURE}

The multiple flow rates test should be considered over the traditional one (single flow rate plus bump flow), even if that lasts longer than this. Because the experiments in several increasing flow rates provide $K_{r}$ and $P_{c}$ curves simultaneously (Bauget et al., 2012).

In the technique proposed by Lenormand and Lenormand (2016), the test starts by injecting water into the sample at constant flow until oil production and differential pressure stabilize. Then, the flow rate is increased until the new stabilization is achieved. This process is repeated using 5 to 10 steps of injection rates. With each rate, additional oil is produced and the average water saturation increases. With these data, it is possible to account for the capillary end effect and for the amount of oil that was retained due to this phenomenon. At the end of the test, $S_{o r}^{r e m}$ is expected to be closer to the real $S_{\text {or }}$ (Gupta \& Manoley, 2016). 
Table 1. Properties of the sample and fluids used in the USS experiment multiple flows.

\begin{tabular}{cccccc}
\hline Sample & $\begin{array}{c}\text { Length } \\
\mathrm{L}(\mathrm{cm})\end{array}$ & $\begin{array}{c}\text { Diameter } \\
\mathrm{D}(\mathrm{cm})\end{array}$ & $\begin{array}{c}\text { Absolute permeability } \\
K_{a b s}(\mathrm{mD})\end{array}$ & $\begin{array}{c}\text { Porosity } \\
\phi(\text { frac.) }\end{array}$ & $\begin{array}{c}\text { Porous Volume } \\
V_{P}\left(\mathrm{~cm}^{3}\right)\end{array}$ \\
\hline Sample 1 & 4.78 & 3.82 & 597 & 0.225 & 11.99 \\
Sample 2 & 4.84 & 3.82 & 602 & 0.227 & 12.24 \\
Sample 3 & 4.9 & 3.82 & 601 & 0.228 & 12.5 \\
\hline
\end{tabular}

Table 2. Physicochemical properties of fluids at $21^{\circ} \mathrm{C}$ and ambient pressure.

\begin{tabular}{ccc}
\hline Fluid & $\begin{array}{c}\text { Density } \\
\rho\left(\mathrm{g} / \mathrm{cm}^{3}\right)\end{array}$ & $\begin{array}{c}\text { Viscosity } \\
\mu(\mathrm{cP})\end{array}$ \\
\hline Oil & 0.856 & 23.0 \\
Brine & 1.142 & 1.48 \\
\hline
\end{tabular}

\section{MATERIALS AND METHODS}

\subsection{Materials}

The rock samples used were homogeneous outcrops of the Berea Buff formation, obtained from Kocurek Industries. To minimize the influence of the type of sample in the tests, the same $20 \mathrm{~cm}$ core was split into smaller cores, approximately 5 $\mathrm{cm}$ each. The basic properties of these samples are shown in Table 1.

EMCA PLUS 70 was the fluid used as oil phase and a brine with a composition equivalent to that of the Brazilian Pre-Salt fields was used as aqueous phase. Physicochemical properties of fluids under test conditions are shown in Table 2.

\subsection{Methods}

The USS water-oil relative permeability experiment at laboratory scale (Figure 2) followed the sequence of procedures proposed by Viegas (2017):

1. Cleaning the sample in Soxhlet apparatus, using methanol and methylbenzene (toluene);

2. The routine core analysis to obtain the basic properties of the samples, such as absolute permeability and effective porosity;

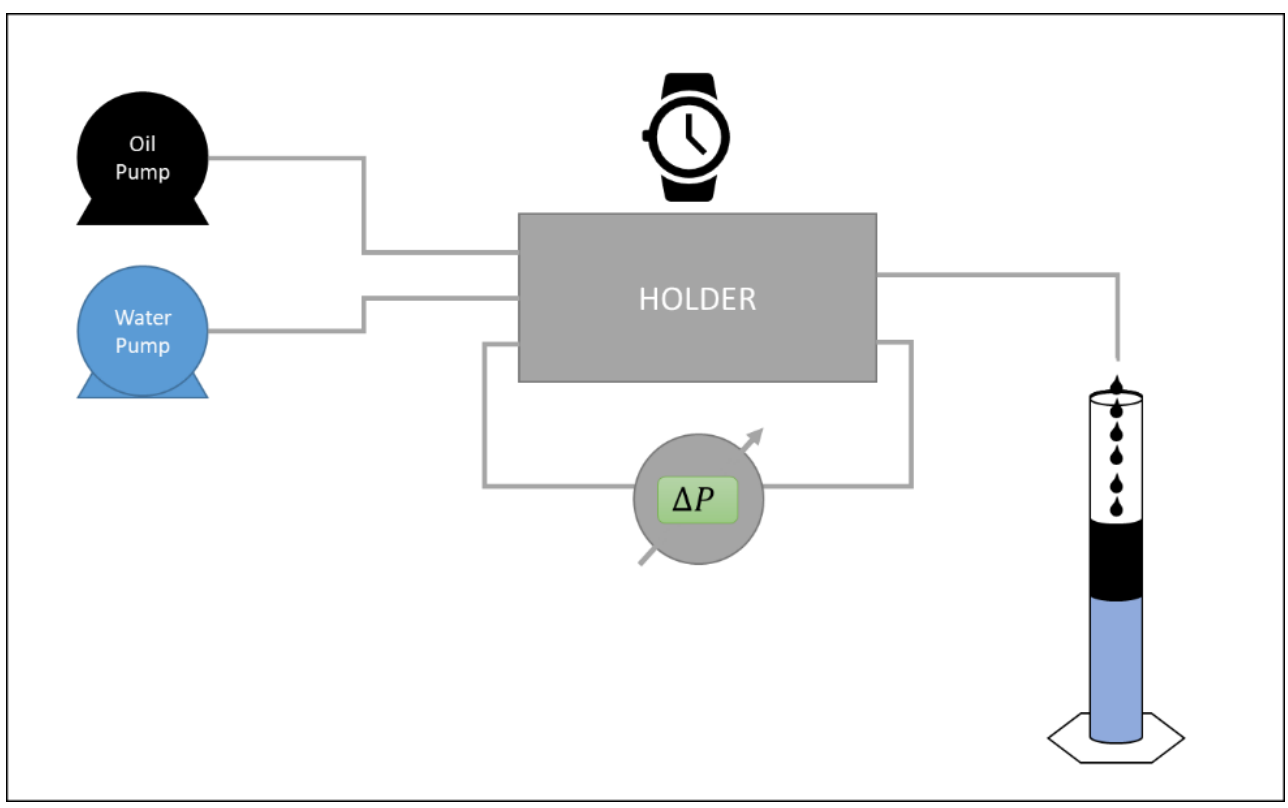

Figure 2. Schematic diagram of the relative permeability equipment under laboratory conditions. 

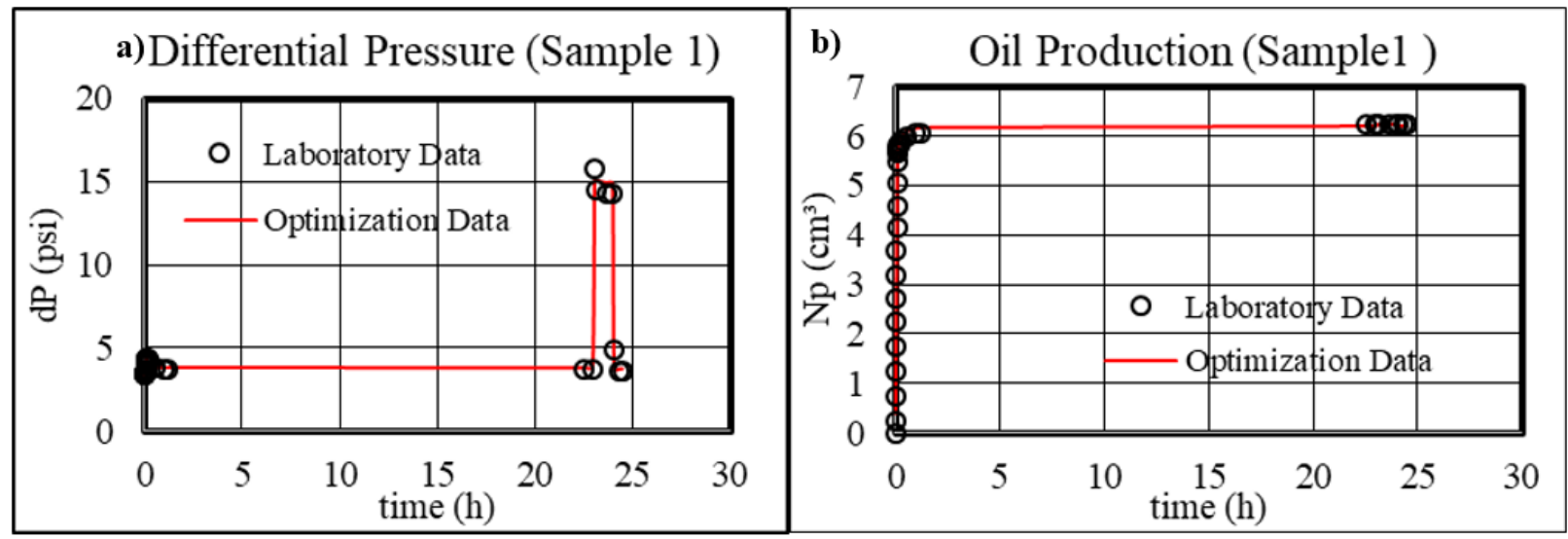

Figure 3. Experimental data obtained in the traditional water-oil relative permeability test with bump flow (points) and data obtained by the history-matching process (solid line) to obtain $\mathrm{Kr}$ and Pc curves. a) Differential pressure versus time. b) Volume of produced oil versus time.

3. Total saturation of the samples with the brine of composition equivalent to the water of formation of the fields of the Brazilian PreSalt;

4. Centrifugation of samples in an oil environment to obtain irreducible water saturation $\left(S_{w i}\right)$;

5. Accommodation of the core sample on a hydrostatic confinement cell, using 1,000 psi of confining pressure;

6. Measurement of effective oil permeability at irreducible water saturation $\left(K_{r o} @ S_{w i}\right)$;

7. Displacement of mineral oil by injection of brine to the state of residual oil saturation $\left(S_{o r}\right)$, with monitoring of oil production $\left(N_{P}\right)$ and differential pressure $(\Delta P)$ :

7.1. With a constant flow of $1 \mathrm{~cm}^{3} / \mathrm{min}$ plus a bump flow of $4.0 \mathrm{~cm}^{3} / \mathrm{min}$ in the traditional test.

7.2. With five flow levels in the multi-step test: $1.0,2.0,4.0,8.0$, and $10 \mathrm{~cm}^{3} / \mathrm{min}$.

8. Measurement of effective water permeability in $S_{\text {or }}$.

Experimental data was used to estimate relative permeability and capillary pressure by history matching. The software CYDAR $^{\circ}$ was used to estimate the parameters of the models used: LET model (Lomeland et al., 2005) for relative permeability and $\log \left(S^{\beta}\right)$ model (CYDAREX, 2018) for capillary pressure.

\section{RESULTS AND DISCUSSIONS}

Figure 3 shows the experimental data from Sample 1, in which water was injected at a flow rate of $1.0 \mathrm{~cm}^{3} / \mathrm{min}$ for 23 hours. At the end of this first injection, $6.25 \mathrm{~cm}^{3}$ of oil was produced. The bump flow, with a flow rate of $4 \mathrm{~cm}^{3} / \mathrm{min}$, was carried out afterwards, and the $\Delta P$ stabilized after 1 hour. Following, there was no additional oil production. Returning to a flow rate of 1.0 $\mathrm{cm}^{3} / \mathrm{min}$, the $\Delta P$ stabilized after $30 \mathrm{~min}$. Thus, the traditional test with the bump flow was completed in $24.5 \mathrm{~h}$.

Figure 4.a shows the capillary pressure curve estimated for the imbibition test. As shown by Abdallah et al. (2007), the sample showed results from a water-wet sample, where the capillary pressure remains positive during most of the saturation range, as shown in Figure 4.a. Thus, water saturation preferably increases first in the smallest pores, due to wetting forces, so the displacement occurs from the smallest to the largest pores, and the water increasingly occupies the throat of pores that were previously filled with oil, as shown in Figure 4.b, which presents the relative permeability.

According to Masalmeh (2012), water-wet samples have very well-defined residual oil saturation and are insensitive to the flow rate, that is, $S_{\text {or }}$ is not affected by the increase in flow rate. Analyzing Figures 3 and 4 , it is possible to infer that the sample is water-wet, so there was no additional production associated with bump flow, so $S_{o r}^{r e m}$ was equal to $S_{o r}^{b m u p}$ (Figure 3.b). 


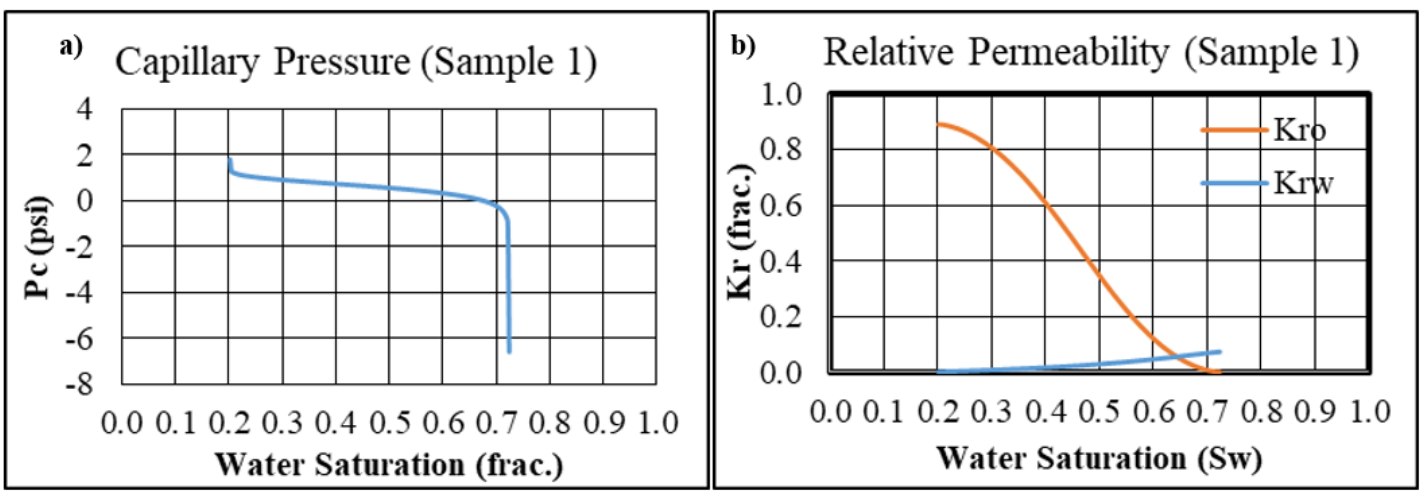

Figure 4. Curves estimated in CYDAR, using history matching. a) Capillary pressure curve as a function of water saturation. b) Relative permeability curves as a function of water saturation.

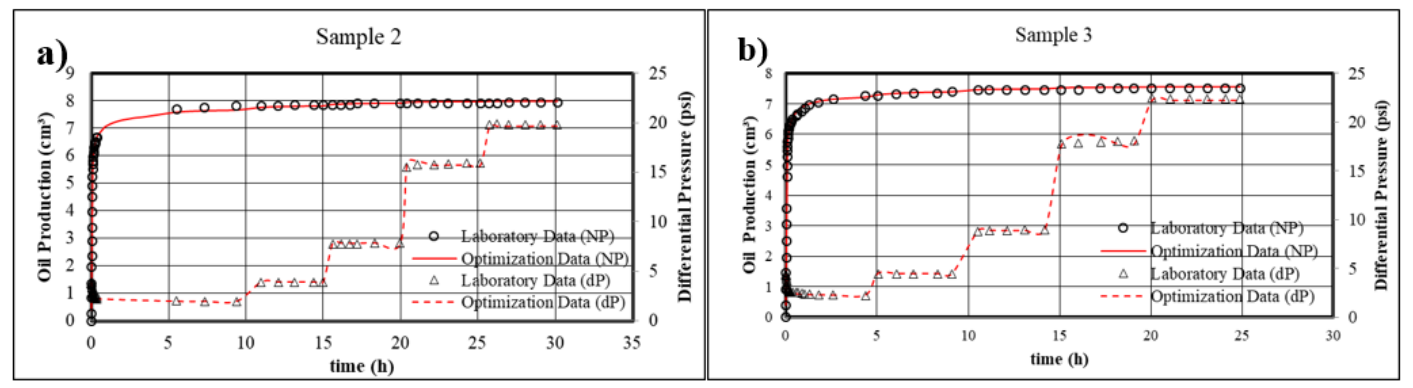

Figure 5. Experimental data obtained in the multi-step water-oil relative permeability test (points) and data obtained by the history-matching process (solid line) to obtain $\mathrm{Kr}$ and Pc curves. a) Sample 2. b) Sample 3.

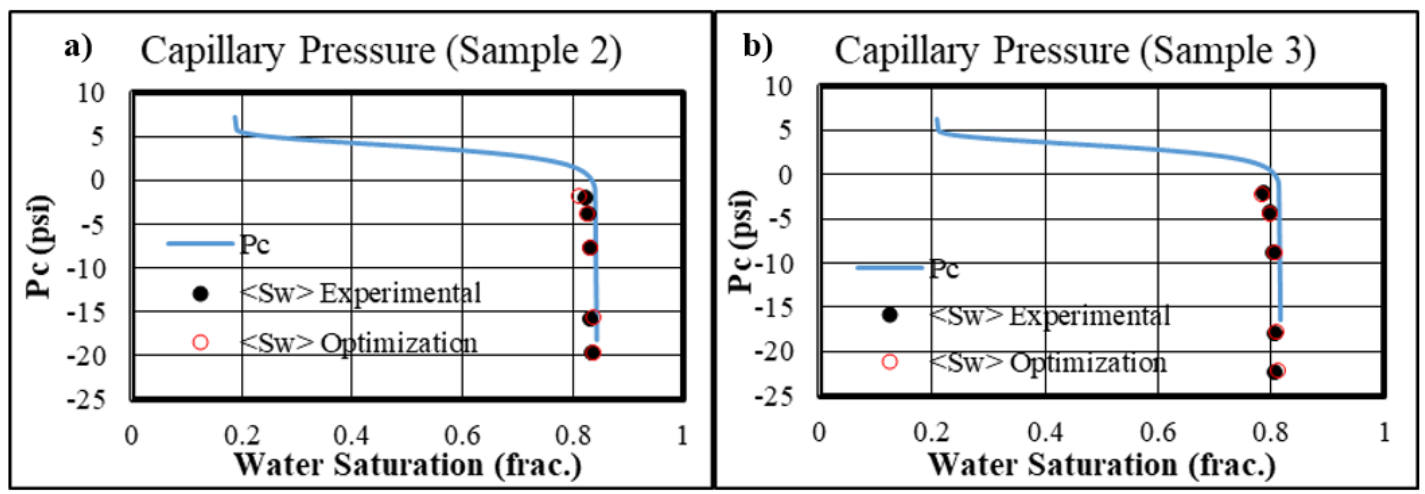

Figure 6. Capillary pressure estimated by history matching versus experimental average water saturation and optimized average water saturation. a) Sample 2. b) Sample 3.

In Figure 5, data of Samples 2 and 3 are presented, which were submitted to the multistep process. In Figure 5.a identifies that in the first test flow, Sample 1, $7.80 \mathrm{~cm}^{3}$ of oil was produced, and, at the end of the 30 -hour test, $7.93 \mathrm{~cm}^{3}$ was produced. That is, even when increasing the flow 10 times, there was a gain of only $1.7 \%$ in the volume of fluid produced; a flow of about 1.0 $\mathrm{cm}^{3} / \mathrm{min}$.

In Sample 3, shown in Figure 5.b, the first flow of $1.0 \mathrm{~cm}^{3} / \mathrm{min}$ produced $7.25 \mathrm{~cm}^{3}$ during the initial
5 hours, ending the test with $7.50 \mathrm{~cm}^{3}$ of displaced oil. Thus, the 10-fold increase in flow provided a small gain of $3.4 \%$ of the oil produced about the initial flow.

Capillary pressure and relative permeability curves, presented in Figure 6 and Figure 7, respectively, fitted the experimental data with precision, as shown in Figure 5 . In Figure 6 , the $P_{c}$ curves are positive in most of the water saturation range, representing water-wet samples. Also, adapting the calculation of the USBM index for the 


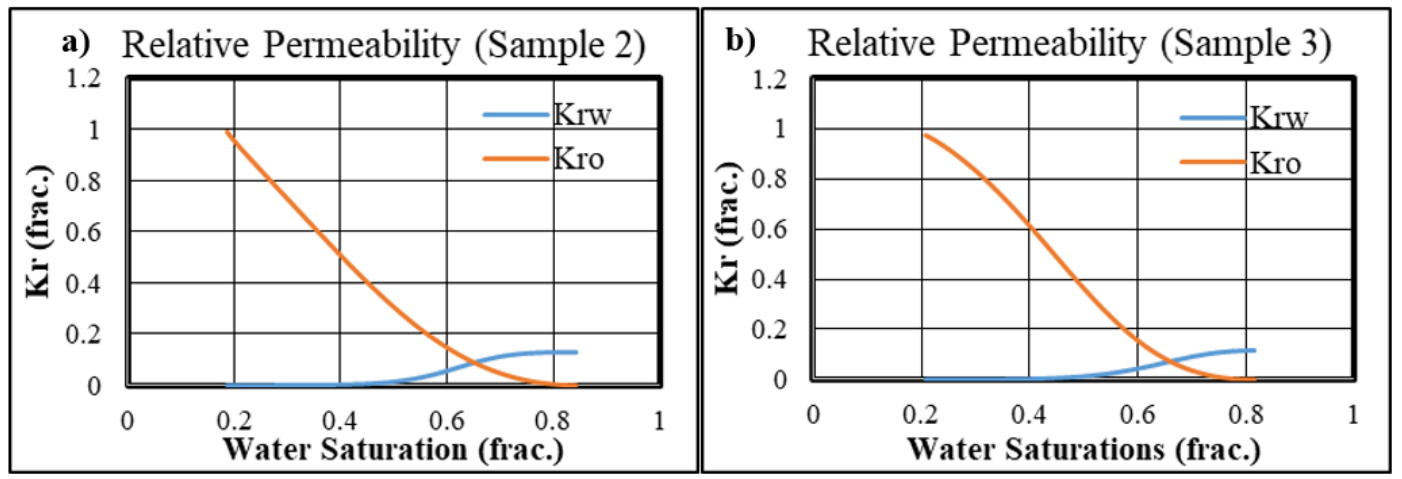

Figure 7. Relative permeability estimated by history matching as a function of water saturation. a) Sample 2. b) Sample 3.

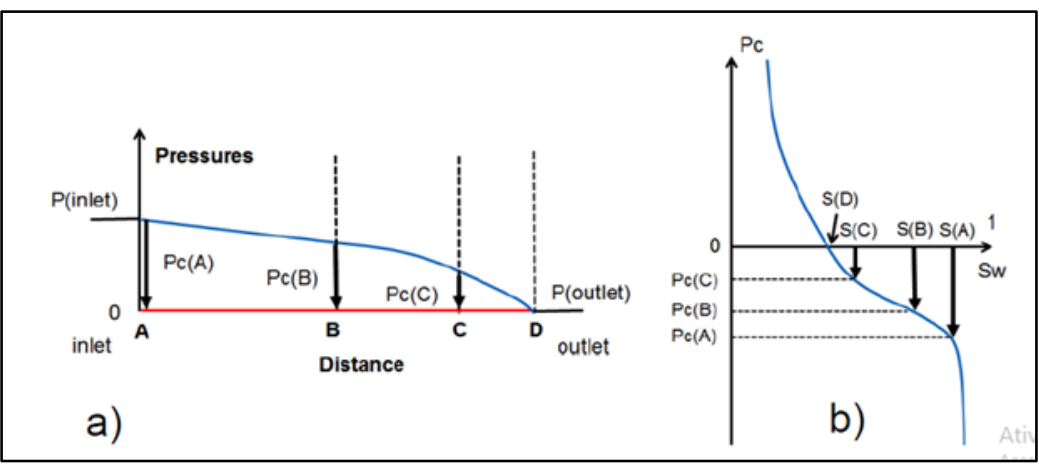

Figure 8. USS displacement. a) Pressure profile at equilibrium (water in blue and oil in red). The arrows represent the capillary pressure in different positions across the sample length. b) Determination of the correspondent water saturation in the capillary pressure curve (Lenormand \& Lenormand, 2016).

imbibition test, which measures the wettability using the areas under the positive and negative capillary pressure curves, this water wettability is confirmed, since the results are values greater than 1 (Abdallah et al., 2007).

Besides, interpreting the $K_{r}$ curves in Figure 7, one can notice that water begins to enter the smaller pores first. As the water saturation increases, the pores are filled from the smallest to the largest sequentially, as well as a preferably wettable sample by water, as explained by Crotti (2008).

The average water saturation $\left\langle S_{w}\right\rangle$ versus capillary pressure data presented in Figure 6 was obtained by the procedure proposed by Lenormand and Lenormand (2016). This procedure assumes that at the end of each flow rate, as oil production stops, the oil phase is not moving, therefore the differential pressure for this phase equals to zero $\left(P_{o}\right)$. This implies that the differential pressure measured across the sample is the water phase differential pressure $\left(P_{w}\right)$ (Figure 8 and Equation 1). Equations 2 and 3 demonstrate how these calculations are performed.

$P_{w}=\Delta P$

$P_{c}=P_{o}-P_{w}=0-\Delta P$

$P_{c}=-\Delta P$

Points of $P_{c}$ vs $\left\langle S_{w}\right\rangle$ were used in CYDAR as experimental constraints to the estimated capillary pressure, improving the solution to the specific problem faced by the history matching process. Comparing experimental and estimated data, it is possible to conclude that the constraint was satisfied with great precision.

Saturation profiles at the end of each flow rate were also obtained by the history-matching process (Figure 9). It is possible to notice that the increase in flow rates causes an increase in the average water saturation and, consequently, an increase in oil production, as shown in Figure 5. 


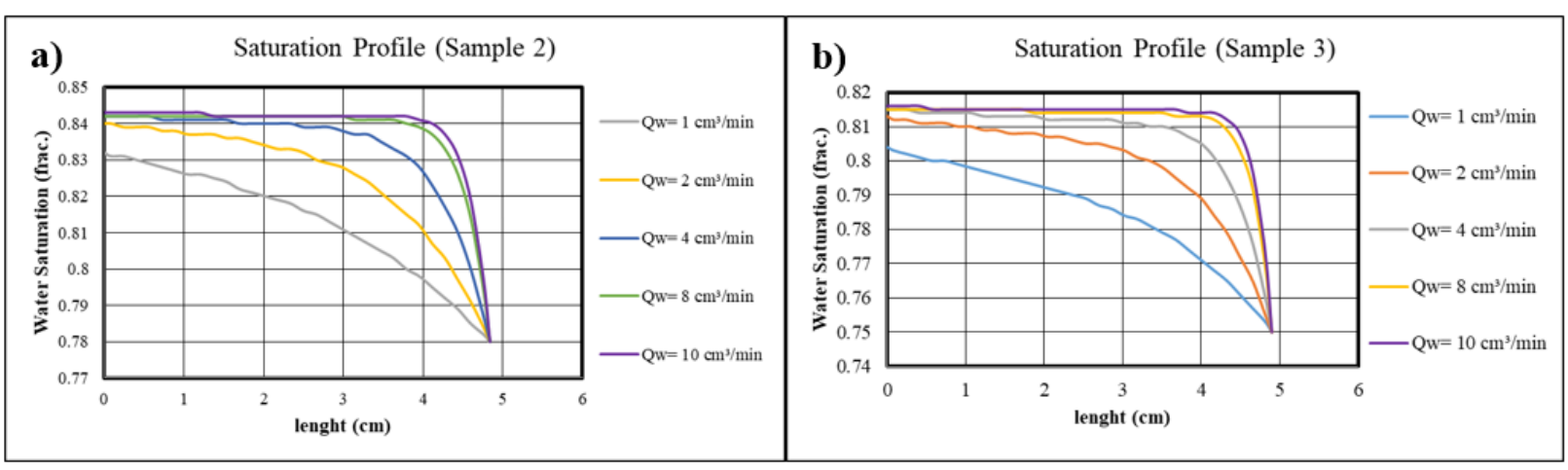

Figure 9. Saturation profile at the end of each flow. a) Sample 2. b) Sample 3.

Also, the saturation profiles become more uniform along the length of the sample as the flow increases. In Figure 9, it is possible to observe that oil is trapped at the end of the core sample, thus, there is a wettability to oil and these samples are mixed-wet (Peters, 2012).

\section{CONCLUSIONS}

Relative permeability experiments were carried out in three sandstone samples of the same petrophysical properties, comparing different methodologies. Sample 1 used a conventional test while Samples 2 and 3 were conducted with multiple flow rates. From the data collected from the samples, it is possible to conclude that:

- In high permeability water-wet samples, the stabilization of the differential pressure and produced volume is achieved in 5 hours, at each imposed flow rate;

- Multiple flow rates methodology can minimize and account for the capillary end-effect, since there is additional production after the first flow, even if minimal;

- Relative permeability and capillary pressure curves obtained simultaneously in the same experiment reduce the problem of nonuniqueness of the solution, associated with the non-linear regression calculations applied in the historical adjustment.

\section{ACKNOWLEDGMENTS}

The authors gratefully acknowledge the support provided by CENPES/PETROBRAS, LRAP/COPPE/UFRJ, and CAPES.

\section{REFERENCES}

Abdallah, W.; Buckley, J. S.; Carnegie, A.; Edwards, J.; Herold, B.; Fordham, E.; Graue, A.; Habashy, T.; Seleznev, N.; Signer, C.; Hussain, H.; Montaron, B.; Ziauddin, M. Fundamentals of wettability. Oilfield Review, Summer 2007, p. 44-61, 2007.

Al-Mjeni, R.; van Wunnik, S. A. P. C.; Edwards, J.; Felber, B. J.; Gurpinar, O.; Miller, G. J.; Hours, C. A.; Jackson, C.; Kristensen, M. R.; Lim, F.; Ramammorty, R. Has the time come for EOR?. Oilfield Review, Winter 2010/2011, v. 22(4), p. 1635, 2010/2011.

Ambrus, J.; Maliska, C.; Hurtado, F. S. V.; Silva, A. F. C. Uma metodologia de estimação de parâmetros aplicada à determinação de curvas de permeabilidade relativa de rochas reservatório. ResearchGate, [s. I.], November 2004. Available at: https://www.researchgate.net/publication/295866386. Accessed on: 21 sept. 2020. (in Portuguese)

Bauget, F.; Gautier, S.; Lenormand, R.; Samouillet, A. Gas-liquid relative permeabilities from one-step and multi-step centrifuge experiments., International Symposium of the Society of Core Analysts, SCA2012-13, Aberdeen, Scotland, UK, p. 1-12, 27 August. 2012.

Crotti, M. A. Motion of fluids in oil \& gas reservoirs. InLab, 2008.

Cruz, D. A. Estudo das curvas de permeabilidade relativa água-óleo considerando o efeito de forças capilares na produção adicional de óleo. 138 f. Dissertação (Mestrado em Engenharia Civil) - Programa de Pós-graduação em Engenharia Civil, COPPE, Universidade Federal do Rio de Janeiro, Rio de Janeiro, 2015. 
Gupta, R.; Maloney, D. R. Intercept method--A novel technique to correct steady-state relative permeability data for capillary end effects. SPE Reservoir Evaluation \& Engineering, SPE-171797PA, v. 19, April 2016. https://doi.org/10.2118/171797$\underline{P A}$

Hadley, G. F.; Handy, L. L. A theoretical and experimental study of the steady state capillary end effect. Fall Meeting of the Petroleum Branch of AIME, SPE-707-G, Los Angeles, California, USA, 14-17 October 1956. https://doi.org/10.2118/707-G

Johnson, E. F.; Bossler, D. P.; Naumann Bossler, V. O. Calculation of relative permeability from displacement experiments. Petroleum Transactions, AIME, v. 216, p. 370-372, 1959. https://doi.org/10.2118/1023-G

Jones, S. C.; Roszelle, W. O. Graphical techniques for determining relative permeability from displacement experiments. Society of Petroleum Engineers, Journal of Petroleum Technology, v. 30(5), SPE-6045-PA, 1978. https://doi.org/10.2118/6045-PA

Lenormand, R.; Lenormand, G. Recommended procedure for determination of relative permeabilities. International Symposium of the Society Core Analysis, SCA004, p. 1-12, Snowmassa, Colorado, USA, 2016.

Lomeland, F.; Ebeltoft, E.; Thomas, W. H. A new versatile relative permeability correlation. Reviewed Proceedings of the 2005 International Symposium of the of the Society of Core Analysts, SCA2005-32, Toronto, Canada, 21-25 August 2005.

CYDAREX. CYDAR Manual: Common Features. CYDAREX, October 2018. Available at: http://www.cydarex.fr/?page_id=23. Accessed on: 16 November 2020.

Masalmeh, S. K. Impact of capillary forces on residual oil saturation and flooding experiments for mixed to oil-wet carbonate reservoirs. SCA2012-11, International Symposium of the Society of Core Analysts, p. 1-14, Aberdeen, Scotland, UK, 27 August 2012.
Peters, E. J. Advanced Petrophysics: Dispersion, Interfacial Phenomena Wettability, Capillarity Capillary Pressure, Relative Permeability. Live Oak Book Company, v. 2, 276 p, June 2012.

Rosa, A. J.; Carvalho, R. S.; Xavier, J. A. D. Engenharia de Reservatórios de Petróleo. Rio de Janeiro, RJ, Brazil: Editora Interciência Ltda., 2006. (in Portuguese)

Rios, E. H.; Ramos, P. F. O.; Compan, A. L. M.; Surmas, R.; Camargo, H. V. R.; Cruz, D. A.; Skinner, R.; Machado, V. F.; Figueiredo, I.; Stael, G. C. Petrofísica laboratorial no suporte à exploração e caracterização de reservatórios. European Association of Geoscientists \& Engineers, Conference Proceedings of V Simpósio Brasileiro de Geofísica, cp-341-00098, November 2012. (in Portuguese)

Ucan, S.; Civan, F.; Evans, R. Uniqueness and simultaneous predictability of relative permeability and capillary pressure by discrete and continuous means. The Journal of Canadian Petroleum Technology, v. 36(4), p. 52-61, 1997.

https://doi.org/10.2118/97-04-05

Viegas, V. T. Comparação entre os regimes transiente e permanente na obtenção de curvas de permeabilidade relativa. 111 p. Dissertação (Mestrado em Engenharia Civil) - Programa de Pósgraduação em Engenharia Civil, COPPE, Universidade Federal do Rio de Janeiro, Rio de Janeiro, 2017. (in Portuguese)

Wang, S. Measurement of relative permeabilities at low saturation using a multi-step drainage process. $309 \mathrm{f}$. PhD Thesis. University of Calgary, Department of Chemical and Petroleum Engineering, Calgary, Alberta, 2014. Available at: https://prism.ucalgary.ca/handle/11023/1336.

Accessed on: 26 October. 2020. 